\title{
Agôn
}

Revue des arts de la scène

Critiques | Saison 2014-2015

\section{Gonzo conférence de Fanny de Chaillé}

Gonzo critique

\section{Caroline Châtelet}

\section{(2) OpenEdition \\ Journals}

Édition électronique

URL : http://journals.openedition.org/agon/3141

DOI : 10.4000/agon.3141

ISSN : 1961-8581

Éditeur

Association Agôn

Référence électronique

Caroline Châtelet, " Gonzo conférence de Fanny de Chaillé », Agôn [En ligne], Critiques, mis en ligne le 28 janvier 2015, consulté le 23 septembre 2020. URL : http://journals.openedition.org/agon/3141 ;

DOI : https://doi.org/10.4000/agon.3141

Ce document a été généré automatiquement le 23 septembre 2020

Association Agôn et les auteurs des articles 


\title{
Gonzo conférence de Fanny de Chaillé
}

\author{
Gonzo critique
}

\author{
Caroline Châtelet
}

\section{RÉFÉRENCE}

Gonzo conférence de Fanny de Chaillé

Du 18 au 20 décembre, Nouveau théâtre de Montreuil

1 C'est en 2007 que j'ai vu pour la première fois Gonzo conférence. Fait (pas si) étrange, je n'ai aucun souvenir de la proposition l'ayant suivi - deux formes étaient présentées ce soir-là à l'atheneum, à Dijon. Fait (peut-être tout aussi) étrange, je me souviens avec pas mal de précision de Gonzo conférence. De son intitulé, de sa conceptrice, l'interprète et chorégraphe Fanny de Chaillé, tout comme de sa forme et de son principe. Soit deux femmes entrant dans la salle. L'une, habillée (Fanny de Chaillé), prend place à un micro situé dans le public. L'autre, nue (Christine Bombal), monte sur une scène, y enfile une culotte, une robe courte, des chaussures. Tandis que l'une lit un texte illustré de deux morceaux de rock, l'autre danse, renvoyant par ses déplacements et gestes à la position d'énonciation de Fanny de Chaillé ou au propos qu'elle développe. Je me souviens avoir aimé l'épure, la simplicité - scène vide, dispositif de «conférence» minimal, spectateurs mis en situation de concert debout devant la scène, mais dont les regards vont de la danseuse à la conférencière. Je me souviens, aussi, du plaisir stimulant suscité par le décalage et le jeu permanent entre le vrai et le faux, tel le playback introductif de Christine Bombal sur les bruits de bouche de Fanny de Chaillé. Il y avait une façon de dire que les choses ne sont pas ce qu'elles semblent être. Voire, ceci, n'est pas un concert de, mais bien un spectacle sur le rock, avec tout ce que le décalage et la distance induits par le théatre peuvent amener. Sauf que non. Là, je triche. Ou plutôt, je reconstruis : en réalité j'avais oublié le début, les bruits de bouche en playback, le jeu entre facticité et authenticité, l'entre-deux permanent. Pour autant, le 19 décembre dernier, devant Gonzo conférence programmé au Nouveau théâtre de Montreuil, tout m'est revenu. «Tout ", soit la simplicité directe, essentielle de la forme, l'interprétation rugueuse de Bombal et sa résonance avec un texte sacrément pertinent. Car en se 
penchant sur les postures du rock, sa mythologie, le rapport entretenu à ses artistes, les attentes et les présupposés dont les rockers sont malgré eux les victimes, les discours qui l'environnent, Fanny de Chaillé le fait à l'aune de son parcours. Fidèle au style du gonzo journalisme, elle scrute le genre à partir de ses choix et expériences personnelles, à la première personne. Avec tout ce que cela comporte de subjectivité, mais aussi de mise à distance. Comme la critique dramatique s'attache en général à regarder les artifices scéniques - costumes, interprétation, lumières, postures - Fanny de Chaillé décortique jusqu'à l'os la machine rock'n roll, s'interrogeant sur ses usages et procédés. À cette réflexion vivante aussi articulée que sensible répond la présence de Christine Bombal. Entre postures de défi, danse au sol nerveuse, passage en revue des attendus d'un concert - riffs, stage diving ${ }^{2}$ - ou playback sur la conférence, la danseuse donne corps au cheminement de la pensée de Fanny de Chaillé, et révèle l'ambiguïté de la supposée sincérité du rock. Mais en usant de son rapport intime au théâtre pour regarder un autre objet, Fanny de Chaillé esquisse du même coup, par ricochet et en filigrane, une réflexion sur l'art dramatique. Et quoique je l'avais oublié, c'est bien cela qui, en 2007 déjà, m'avait intéressé. Peut-être parce se niche entre ultra-subjectivité, mise à distance et regard critique une position possible du critique dramatique.

\section{Gonzo conférence, de Fanny de Chaillé}

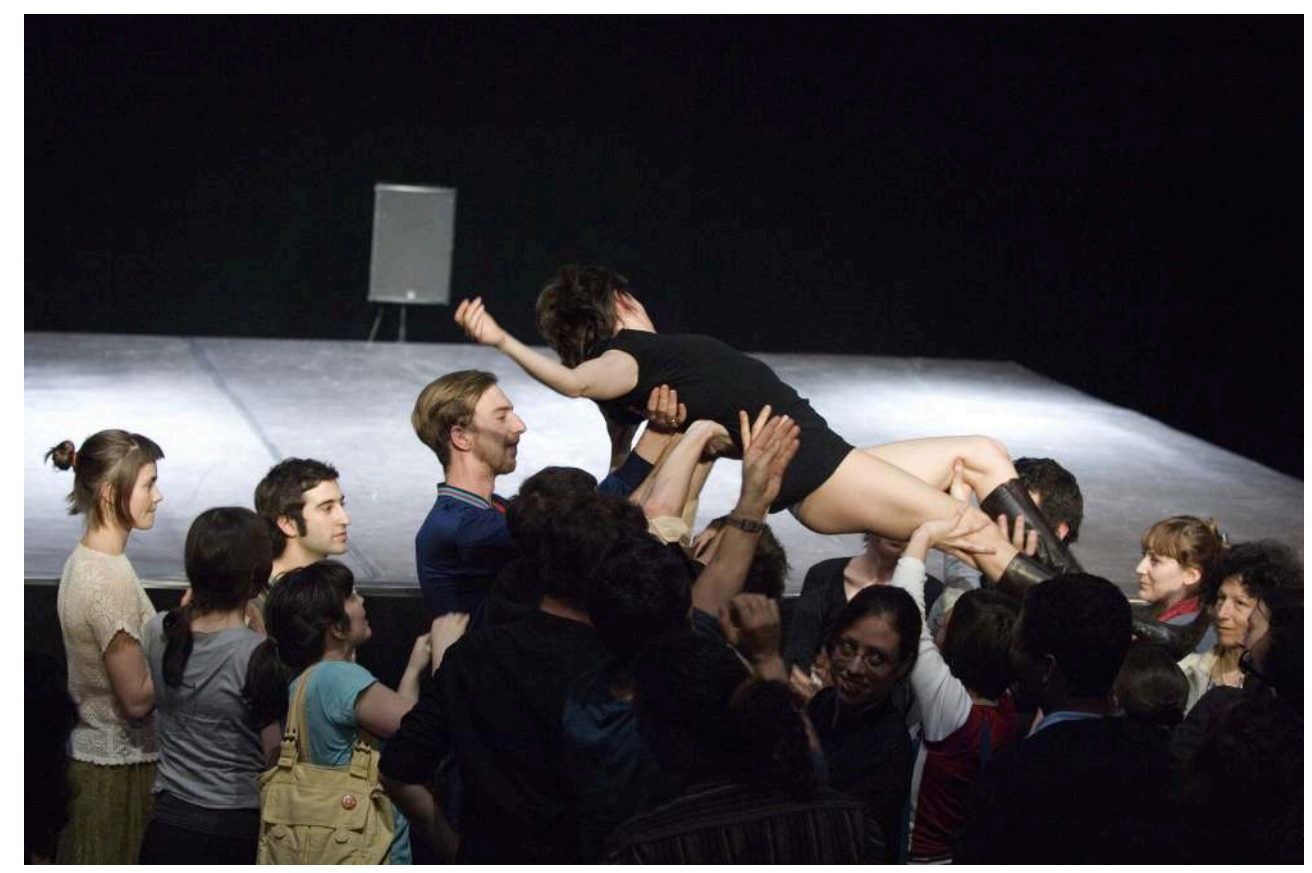

Du 18 au 20 décembre, Nouveau théâtre de Montreuil

www.nouveau-theatre-montreuil.com www.fannydechaille.fr/ 


\section{NOTES}

1. Le "gonzo journalisme" est un journalisme ultra-subjectif: utilisation de la première personne, introspection, évocation de soi afin de renseigner le lecteur sur les différents faits influant sur sa perception.

2. Fait de plonger dans le public depuis la scène afin de se faire porter par le public. 